\title{
EDUKASI HIPERTENSI KEPADA MASYARAKAT DESA PEMURUS RT 002 SECARA DARING MENGGUNAKAN MEDIA AUDIO VISUAL
}

\author{
Muhammad Irfan'), Eva Mujiarahmah'), Riska Iriyanti'1), Noor Ahda Fadillah'1) \\ 1)Program Studi Kesehatan Masyarakat, Fakultas Kedokteran, Universitas Lambung Mangkurat, Banjarbaru, \\ Kalimantan Selatan, Indonesia \\ Corresponding author : Muhammad Irfan \\ E-mail : Irfan.m252525@gmail.com
}

Diterima 30 April 2021, Direvisi 22 Mei 2021, Disetujui 25 Mei 2021

\begin{abstract}
ABSTRAK
Hipertensi sering disebut dengan "silent killer" atau pembunuh diam-diam karena terjadi tanpa gejala. Hipertensi adalah suatu keadaan dimana terjadi peningkatan tekanan darah di atas ambang batas normal yaitu $120 / 80 \mathrm{mmHg}$. Metode yang digunakan dalam kegiatan pengabdian ini adalah penyuluhan secara daring melalui WhatsApp. Pengabdian ini bertujuan untuk memberikan edukasi kepada masyarakat agar lebih mengenal hipertensi dan dapat melakukan upaya-upaya pencegahan dan pengendalian secara mandiri. Peserta penyuluhan terdiri dari masyarakat Desa Pemurus RT 002 Kecamatan Aluh-aluh Kabupaten Banjar sebanyak 12 orang. Edukasi diberikan menggunakan media audio visual berupa video edukasi yang berisi informasi-informasi dasar terkait hipertensi. Sebelum materi diberikan peserta mengisi pre-test terlebih dahulu dan di akhir kegiatan peserta akan mengisi post-test. Hasil uji paired sample $t$-test didapatkan bahwa aspek pengetahuan mengalami peningkatan secara signifikan setelah diberikan edukasi. Sedangkan aspek sikap dan perilaku tidak mengalami peningkatan secara signifikan.
\end{abstract}

Kata kunci: hipertensi; daring; edukasi; audio visual

\begin{abstract}
Hypertension is often referred to as the "silent killer" because it occurs without symptoms. Hypertension is a condition where there is an increase in blood pressure above the normal threshold of $120 / 80 \mathrm{mmHg}$. The method used in this service activity is online counseling via WhatsApp. This service aims to provide education to the community so that they are more familiar with hypertension and can carry out prevention and control efforts independently. The counseling participants consisted of 12 people from the RT 002 Desa Pemurus, Kecamatan Aluh-aluh Kabupaten Banjar. Education is given using audio-visual media in the form of educational videos which contain basic information related to hypertension. Before the material is given the participants fill out the pre-test first and at the end of the activity the participants will fill out the post-test. The results of the paired sample t-test showed that the knowledge aspect had increased significantly after being given education. Meanwhile, the attitude and behavior aspects did not increase significantly.
\end{abstract}

Keywords: hypertension; online; education; audio-visual.

\section{PENDAHULUAN}

Hipertensi atau tekanan darah tinggi merupakan suatu kondisi medis dengan meningkatnya konstraksi pembuluh darah arteri sehingga terjadi resistensi aliran darah yang meningatkan tekanan darah terhadap dinding pembuluh darah. Hipertensi sering disebut dengan "silent killer" atau pembunuh diam-diam karena terjadi tanpa gejala. Ketika gejala timbul, hipertensi sudah menjadi penyakit yang harus di terapi seumur hidup (Kemenkes RI, 2013). Hipertensi atau yang dikenal dengan nama penyakit darah tinggi adalah suatu keadaan dimana terjadi peningkatan tekanan darah di atas ambang batas normal yaitu $120 / 80 \mathrm{mmHg}$.
Menurut WHO (Word Health Organization), batas tekanan darah yang dianggap normal adalah kurang dari 130/85 mmHg. Bila tekanan darah sudah lebih dari $140 / 90 \mathrm{mmHg}$ dinyatakan hipertensi (batas tersebut untuk orang dewasa di atas 18 tahun) (Adib, 2009). Hipertensi dapat diklasifikasikan menjadi 2 jenis, yaitu hipertensi primer $(90 \%$ kasus hipertensi) yang penyebabnya tidak diketahui dan hipertensi sekunder (10\%) yang disebabkan oleh penyakit ginjal, penyakit endokrin, penyakit jantung dan gangguan ginjal (Sidabutar and Wiguno, 1999). Menurut JNC VII Report 2003, diagnosis hipertensi ditegakkan apabila didapatkan tekanan darah sistolik 
(TDS) $\geq 140 \mathrm{mmHg}$ dan atau tekanan darah diastolik $(T D D) \geq 90 \mathrm{mmHg}$ pada dua kali pengukuran dalam waktu yang berbeda (Kemenkes RI, 2018).

Penyakit hipertensi tahun demi tahun terus mengalami peningkatan. Tidak hanya di Indonesia, namun juga di dunia. Sebanyak 1 milyar orang di dunia atau 1 dari 4 orang dewasa menderita penyakit ini. Bahkan, diperkirakan jumlah penderita hipertensi akan meningkat menjadi 1,6 milyar menjelang tahun 2025. Kurang lebih $10-30 \%$ penduduk dewasa di hampir semua negara mengalami penyakit hipertensi, dan sekitar $50-60 \%$ penduduk dewasa dapat dikategorikan sebagai mayoritas utama yang status kesehatannya akan menjadi lebih baik bila dapat dikontrol tekanan darahnya (Adib, 2009).

Badan Kesehatan Dunia (WHO) menyebutkan jumlah penderita hipertensi akan terus meningkat seiring dengan jumlah penduduk yang bertambah pada 2025 mendatang diperkirakan sekitar $29 \%$ warga dunia terkena hipertensi. WHO menyebutkan negara ekonomi berkembang memiliki penderita hipertensi sebesar $40 \%$ sedangkan negara maju hanya $35 \%$, kawasan Afrika memegang posisi puncak penderita hipertensi, yaitu sebesar $40 \%$. Kawasan Amerika sebesar $35 \%$ dan Asia Tenggara 36\%. Kawasan Asia penyakit ini telah membunuh 1,5 juta orang setiap tahunnya. Hal ini menandakan satu dari tiga orang menderita hipertensi. Sedangkan di Indonesia cukup tinggi, yakni mencapai 32\% dari total jumlah penduduk (WHO, 2013).

Kemenkes (2013) melaporkan, bahwa hipertensi merupakan penyebab kematian nomor 3 setelah stroke dan tuberkulosis, dimana proporsi kematiannya mencapai $6,7 \%$ dari populasi kematian pada semua umur di Indonesia. Hasil Riset Kesehatan Dasar (Riskesdas) Balitbangkes tahun 2013 menunjukkan prevalensi hipertensi secara nasional mencapai $25,8 \%$. Penderita hipertensi di Indonesia diperkirakan sebesar 15 juta tetapi hanya $4 \%$ yang hipertensi terkendali. Hipertensi terkendali adalah mereka yang menderita hipertensi dan mereka tahu sedang berobat untuk itu. Sebaliknya sebesar $50 \%$ penderita tidak menyadari diri sebagai penderita hipertensi, sehingga mereka cenderung untuk menderita hipertensi yang lebih berat (Tarigan, Lubis \& Syarifah, 2018).

Hasil Riskesdas 2018 menunjukkan prevalensi penyakit tidak menular mengalami kenaikan jika dibandingkan dengan Riskesdas 2013, antara lain kanker, stroke, penyakit ginjal kronis, diabetes melitus, dan hipertensi. Prevalensi hipertensi berdasarkan hasil pengukuran pada penduduk umur $\geq 18$ tahun menurut Provinsi terkhusus Kalimantan Selatan tertinggi diantara Provinsi yang ada di Indonesia yaitu $44,1 \%$ (Tarigan, Lubis \& Syarifah, 2018).

Desa Pemurus RT 002 Kecamatan Aluh-Aluh merupakan tempat Pengalaman Belajar Lapangan (PBL) yang dilakukan secara bertahap dari pengalaman belajar I dan II. Berdasarkan hasil diagnosa komunitas didapatkan tiga masalah kesehatan yang perlu disosialisasikan kepada masyarakat sekaligus didiskusikan untuk menentukan permasalahan mana yang menjadi masalah prioritas untuk ditangani. Adapun ketiga permasalahan tersebut ialah hipertensi (18,4\%), KEK (Kekurangan Energi Kronis) pada remaja putri $(80 \%)$, dan pengelolahan air minum yang tidak baik (36\%). Penentuan tiga masalah tersebut didapatkan dengan melihat tingkat keseriusan masalah, angka kesakitan, dan dampak dalam jangka panjang. Setelah dikoordinasikan lebih lanjut dengan masyarakat yang ada disana didapatkan bahwa pemecahan masalah yang dipilih masyarakat yaitu dilakukan kegiatan edukasi terkait hipertensi serta pembuatan dan pelaksanaan Pos Anti Hipertensi sebagai sarana masyarakat untuk mendapatkan informasi mengenai hipertensi sekaligus tempat untuk memeriksa tekanan darah agar tidak harus mengunjungi fasilitas pelayanan kesehatan.

Adapun kegiatan yang dilakukan selama PBL II berlangsung secara umum terbagi menjadi 2, yaitu: 1) Edukasi Tentang Hipertensi dan Penggunaan Alat Sphygmomanometer Digital, 2) Pembentukan dan Pelaksanan Pos Anti Hipertensi. Adapun tujuan dari dua kegiatan ini untuk meningkatkan pengetahuan dan pemahaman masyarakat terkait dengan hipertensi, menyadarkan masyarakat bahwa pentinganya selalu melakukan pemeriksaan tekanan darah, mampu mengenali gejala hipertensi, meningkatkan kesadaran masyarakat dalam memeriksakan tekanan darahnya secara rutin.

\section{METODE}

Pelaksanaan kegiatan pengabdian kepada masyarakat dilakukan di RT 002 Desa Pemurus Kecamatan Aluh-aluh Kabupaten Banjar yang dilakukan secara daring yaitu melalui WhatsApp. Metode yang digunakan dalam kegiatan ini adalah penyuluhan secara online (daring). Kegiatan berlangsung selama kurang lebih 6 minggu yakni dari bulan Oktober hingga Desember 2020 yang diikuti sebanyak 12 orang dari awal hingga akhir kegiatan. Tahapan-tahapan dalam pelaksanaan penyuluhan yaitu terdiri dari: 1) Tahap Prakegiatan (Persiapan), 2) Tahap Pelaksanaan 
Kegiatan, 3) Tahap Monitoring dan Evaluasi. Kegiatan persiapan yang dilakukan antara lain sebagai berikut: Proses awal dengan menyiapkan keperluan untuk kegiatan penyuluhan, seperti pre-test dan post-test serta materi penyuluhan yang disajikan dalam bentuk media audio visual. Kemudian memasuki tahap pelaksanaan yaitu proses penyuluhan berbasis online menggunakan WhatsApp. Kegiatan pertama yaitu dengan membagikan pre-test menggunakan google form. Selanjutnya pemberian materi dalam bentuk audio visual dan di akhir diberikan kembali post-test. Tahap monitoring dilakukan dengan melakukan observasi dari keaktifan peserta dalam bertanya atau tanggapan lainnya dari materi yang telah dibagikan. Bentuk evaluasi dari kegiatan penyuluhan yaitu melihat dari hasil pre-test dan post-test untuk menilai keberhasilan kegiatan penyuluhan yang dilakukan. Apakah ada peningkatan pengetahuan, sikap dan perilaku masyarakat mengenai penyakit hipertensi setelah penyuluhan diberikan.

\section{HASIL DAN PEMBAHASAN}

Peserta kegiatan penyuluhan berjumlah 12 orang dan dari berbagai golongan usia dan jenis kelamin. Rata-rata usia peserta penyuluhan dapat dilihat pada Tabel 1 berikut.

Tabel 1. Rata-rata Usia Peserta Penyuluhan

\begin{tabular}{ccccc}
\hline $\begin{array}{c}\text { Variab } \\
\text { el }\end{array}$ & Mean & SD & $\begin{array}{c}\text { Minim } \\
\text { um }\end{array}$ & $\begin{array}{c}\text { Maksi } \\
\text {-mum }\end{array}$ \\
\hline Umur & 30,17 & 2,83 & 20 & 48 \\
\hline
\end{tabular}

Distribusi jenis kelamin peserta penyuluhan dapat dilihat pada Tabel 2 berikut.

Tabel 2. Distribusi dan Frekuensi Jenis Kelamin Peserta Penyuluhan

\begin{tabular}{ccc}
\hline $\begin{array}{c}\text { Jenis } \\
\text { Kelamin }\end{array}$ & Frekuensi & $\begin{array}{c}\text { Persentase } \\
(\%)\end{array}$ \\
\hline Laki-laki & 5 & 41,67 \\
\hline Perempuan & 7 & 58,33 \\
\hline Jumlah & 12 & 100 \\
\hline
\end{tabular}

Informasi yang diberikan terkait hipertensi mencakup dari definisi, klasifikasi hipertensi, faktor risiko, cara mencegah, cara mengendalikan serta pemberian pelatihan menggunakan sphygmomanometer digital. Sebelum penyampaian materi dilakukan peserta akan diberikan pre-test terlebih dahulu. Setelah semua materi disampaikan selanjutnya diberikan post-test untuk melihat ada tidaknya perubahan nilai pengetahuan, sikap dan perilaku peserta. Pre-test dan post-test diberikam dalam bentuk google form yang berisi pertanyaan untuk mengukur pengetahuan, sikap dan perilaku peserta.

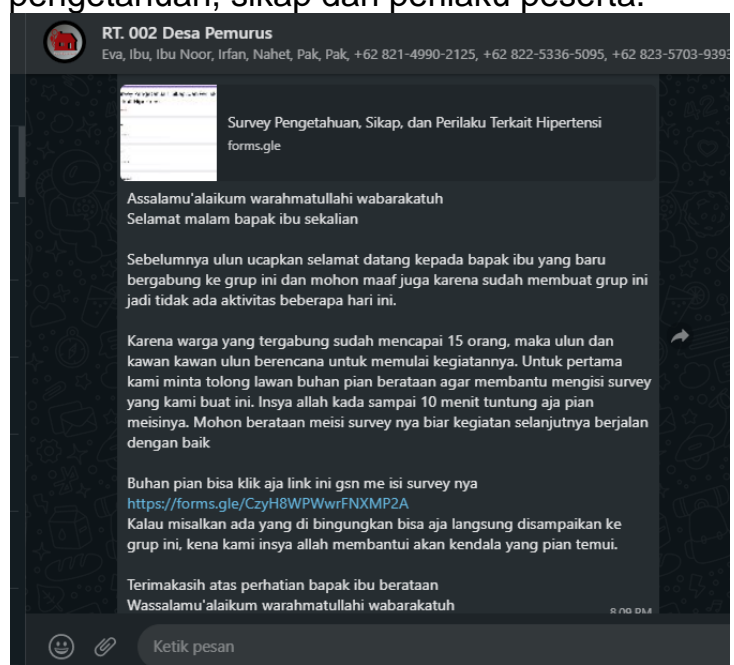

Gambar 1. Penyebaran Link Google Form melalui WhatsApp

Materi disampaikan dalam bentuk audio visual yaitu berupa video yang dibuat oleh panitia kegiatan. Materi terbagi ke dalam 4 video, 3 video berisi informasi-informasi mengenai hipertensi dan 1 video berisi mengenai tata cara menggunakan sphygmomanometer digital. Video dikirimkan secara berkala yakni setiap 1 minggu sekali. Hal ini bertujuan agar peserta dapat lebih mudah dalam mencerna informasi yang didapat. Penyampain di dalam video dibuat dengan bahasa yang sesederhana mungkin dan setiap video yang dikirimkan akan diberikan penjelasan singkat dari panitia terkait isi videonya.

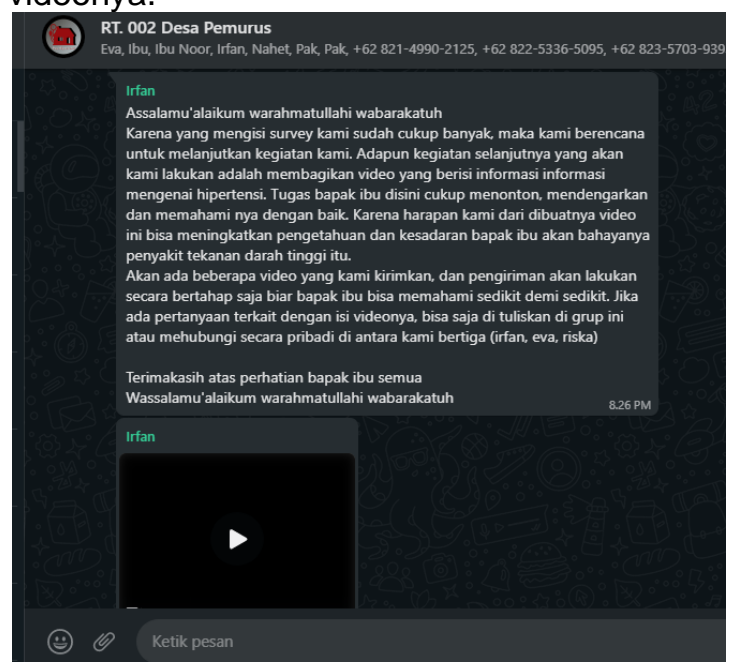

Gambar 2. Pemberian Materi dengan Media Berupa Video Edukasi

Pengategorian hasil pre-test dan posttest aspek pengetahuan dapat dilihat pada Tabel 3 berikut. 
Tabel 3. Hasil Distribusi dan Frekuensi Aspek Pengetahuan Peserta Sebelum dan Sesudah Dilakukan Penyuluhan

\begin{tabular}{|c|c|c|c|c|}
\hline \multirow{2}{*}{$\begin{array}{c}\text { Pengetahua } \\
\text { n tentang } \\
\text { Hipertensi }\end{array}$} & \multicolumn{2}{|c|}{ Sebelum } & \multicolumn{2}{|c|}{ Sesudah } \\
\hline & $\begin{array}{l}\text { Frek } \\
\text { u- } \\
\text { ensi }\end{array}$ & $\begin{array}{c}\text { Pers } \\
\text { en- } \\
\text { tase } \\
(\%)\end{array}$ & $\begin{array}{l}\text { Frek } \\
\text { u- } \\
\text { ensi }\end{array}$ & $\begin{array}{c}\text { Pers } \\
\text { en- } \\
\text { tase } \\
(\%)\end{array}$ \\
\hline Baik & 3 & 25 & 11 & 91,67 \\
\hline Cukup & 9 & 75 & 1 & 8,33 \\
\hline Kurang & 0 & 0 & 0 & 0 \\
\hline Jumlah & 12 & 100 & 12 & 100 \\
\hline
\end{tabular}

Pada Tabel 3 menunjukkan menunjukkan bahwa pengetahuan masyarakat tentang hipertensi sebelum diberikan penyuluhan tentang hipertensi sebesar 25\% pada kategori baik dan $75 \%$ pada kategori cukup. Setelah dilakukan penyuluhan, persentase peserta dengan pengetahuan baik meningkat menjadi $91,67 \%$ dan persentase peserta dengan pengetahuan cukup menjadi $8,33 \%$. Artinya ada peningkatan persentase aspek pengetahuan masyarakat mengenai hipertensi. Setiap poin pertanyaan yang diberikan kepada peserta rata-rata mengalami peningkatan jumlah jawaban benar setelah diberikan edukasi. Poin pertanyaan mengenai pengetahuan terhadap macam-macam faktor risiko hipertensi mengalami peningkatan yang paling besar setelah diberikan edukasi.

Tabel 4. Hasil Distribusi dan Frekuensi Aspek Sikap Peserta Sebelum dan Sesudah Dilakukan Penyuluhan

\begin{tabular}{|c|c|c|c|c|}
\hline \multirow{2}{*}{$\begin{array}{l}\text { Pengetahua } \\
\text { n tentang } \\
\text { Hipertensi }\end{array}$} & \multicolumn{2}{|c|}{ Sebelum } & \multicolumn{2}{|c|}{ Sesudah } \\
\hline & $\begin{array}{l}\text { Frek } \\
\text { u- } \\
\text { ensi }\end{array}$ & $\begin{array}{l}\text { Pers } \\
\text { en- } \\
\text { tase } \\
(\%)\end{array}$ & $\begin{array}{l}\text { Frek } \\
\text { u- } \\
\text { ensi }\end{array}$ & $\begin{array}{c}\text { Pers } \\
\text { en- } \\
\text { tase } \\
(\%)\end{array}$ \\
\hline Baik & 8 & 66,67 & 9 & 75 \\
\hline Cukup & 4 & 33,33 & 3 & 25 \\
\hline Kurang & 0 & 0 & 0 & 0 \\
\hline Jumlah & 12 & 100 & 12 & 100 \\
\hline
\end{tabular}

Berdasarkan Tabel 4 sikap masyarakat mengenai hipertensi sebelum diberikan penyuluhan sebesar $66,67 \%$ kategori baik dan kategori cukup sebesar 33,33\%. Setelah diberikan penyuluhan terjadi perubahan untuk kategori baik menjadi $75 \%$ dan kategori cukup menjadi $25 \%$. Sikap peserta setelah diberikan penyuluhan masih terdapat sikap tidak sesuai dengan pernyataan yang diajukan. Paling banyak tidak sesuai ditemukan pada pernyataan faktor risiko hipertensi.
Tabel 5. Hasil Distribusi dan Frekuensi Aspek Perilaku Peserta Sebelum dan Sesudah Dilakukan Penyuluhan

\begin{tabular}{ccccc}
\hline $\begin{array}{c}\text { Pengetahua } \\
\text { n tentang } \\
\text { Hipertensi }\end{array}$ & $\begin{array}{c}\text { Sebelum } \\
\text { Urek } \\
\text { u- } \\
\text { ensi }\end{array}$ & $\begin{array}{c}\text { Pers } \\
\text { en- } \\
\text { tase } \\
(\%)\end{array}$ & $\begin{array}{c}\text { Frek } \\
\text { u- } \\
\text { ensi }\end{array}$ & $\begin{array}{c}\text { Pers } \\
\text { en- } \\
\text { tase } \\
(\%)\end{array}$ \\
\hline Baik & 1 & 8,33 & 3 & 25 \\
\hline Cukup & 4 & 33,33 & 3 & 25 \\
\hline Kurang & 7 & 58,33 & 6 & 50 \\
\hline Jumlah & 12 & 100 & 12 & 100 \\
\hline
\end{tabular}

Perilaku masyarakat sebelum dilakukan penyuluhan untuk kategori baik sebesar 8,33\%, kategori cukup 33,33\% dan kurang $58,33 \%$. Setelah diberikan penyuluhan terdapat perubahan menjadi $25 \%$ kategori baik, $25 \%$ kategori cukup dan 50\% kategori kurang. Setelah diberikan penyuluhan masih banyak peserta yang menyatakan belum melakukan perilaku pencegahan atau pengendalian hipertensi dengan baik.

Tabel 6. Hasil Analisis Paired sample t-test Sebelum dan Sesudah Diberikan Penyuluhan

\begin{tabular}{cc}
\hline Aspek & $\boldsymbol{P}$-value \\
\hline Pengetahun & 0,015 \\
\hline Sikap & 0,366 \\
\hline Perilaku & 0,455 \\
\hline
\end{tabular}

Hasil analisis paired sample t-test pada Tabel 6 berdasarkan nilai pre-test dan post-test menunjukkan nilai signifikansi sebesar 0,015 $(<0,05)$. Hal ini menunjukkan bahwa ada pengaruh terhadap pengetahuan masyarakat setelah diberikan penyuluhan.

Hasil analisis paired sample t-test pada untuk aspek sikap menunjukkan nilai signifikansi sebesar 0,366 $(>0,05)$. Hal ini menunjukkan bahwa tidak ada pengaruh terhadap sikap masyarakat terkait hipertensi setelah diberikan penyuluhan.

Hasil analisis paired sample t-test pada untuk aspek perilaku menunjukkan nilai signifikansi sebesar 0,455 $(>0,05)$. Hal ini menunjukkan bahwa juga tidak ada pengaruh terhadap perilaku masyarakat terkait hipertensi setelah diberikan penyuluhan.

Penyuluhan berasal dari suluh yang artinya barang yang digunakan sebagai penerangan. Adapun penyuluhan menurut (Ban, 1990) dalam (Febriyanti N \& Nugraha, 2020) menyatakan penyuluhan merupakan sebuah intervensi sosial yang melibatkan penggunaan komunikasi informasi secara sadar untuk membantu masyarakat membentuk pendapat mereka sendiri dan mengambil keputusan dengan baik. Dalam pengabdian ini bentuk intervensi yang diberikan berupa pemberian edukasi dengan harapan 
agar masyarakat dapat mencegah hipertensi atau mengendalikannya bagi yang sudah terkena.

Pengetahuan peserta penyuluhan mengalami peningkatan secara signifikan. Peningkatan pengetahuan masyarakat mengenai hipertensi dengan melakukan penyuluhan memberikan hasil ada perubahan yang berarti antara sebelum dan sesudah penyuluhan dilakukan. Penyuluhan memiliki pengaruh terhadap peningkatan pengetahuan mengenai hipertensi (Ulya, Iskandar \& Asih, 2017; Isnaini \& Purwito, 2019). Pengetahuan seseorang yang baik berpengaruh terhadap tindakan pengendalian tekanan darah yang baik seperti berolahraga, konsumsi sayur dan buah serta menjaga berat badan (Anggreani \& Nasution, 2020). Terdapat 3 faktor yang menyebabkan terjadinya perubahan perilaku seseorang, yaitu (1) kesiapan psikologis, ditentukan oleh tingkat pengetahuan dan kepercayaan, (2) adanya tekanan positif dari individu maupun kelompok, (3) dukungan lingkungan (Isnaini \& Purwito, 2019).

Sikap peserta setelah diberikan penyuluhan mengalami peningkatan namun tidak signifikan. Sikap merupakan bagian dari faktor predisposisi yang berpengaruh terhadap perilaku seseorang (Tarigan, Lubis \& Syarifah, 2018). Pendidikan kesehatan dapat memberikan pengaruh terhadap sikap apabila informasi yang diberikan jelas, sederhana, dan bisa atau mudah ditangkap oleh peserta. Frekuensi pemberian informasi juga memberikan pengaruh terhadap sikap, semakin sering informasi terkait hipertensi diberikan maka sikap seseorang akan dapat berubah (Sunarmi \& Afrida, 2019).

Perilaku peserta penyuluhan setelah diberikan penyuluhan terjadi perubahan namun tidak signifikan. Terjadinya perubahan perilaku seseorang ada banyak hal yang mempengaruhi. Diantaranya sistem kepribadian, pengalaman, adat istiadat dan fasilitas yang tersedia (Isnaini \& Purwito, 2019). Masyarakat Desa Pemurus masih sangat memegang teguh adat dan kebiasaan yang menjadi faktor risiko hipertensi, seperti sering mengosumsi makanan asin dan manis.

\section{SIMPULAN DAN SARAN}

Kegiatan Pengalaman Belajar Lapangan yang dilaksanakan di Desa Pemurus RT 002 Kecamatan Aluh-aluh ini dilaksanakan selama 6 minggu, dengan metode daring. Adapun untuk pembahasan yang diambil adalah terkait Hipertensi. Sebelum disampaikan materi, peserta akan diberikan pre-test terlebih dahulu. Setelah semua materi disampaikan diberikan post-test untuk melihat ada tidaknya perubahan nilai pengetahuan, sikap dan perilaku peserta. Dengan hasil Pengetahuan peserta penyuluhan mengalami peningkatan secara signifikan. Sikap peserta setelah diberikan penyuluhan mengalami peningkatan namun tidak signifikan serta Perilaku peserta penyuluhan setelah diberikan penyuluhan terjadi perubahan namun tidak signifikan. Saran kepada peserta kegiatan agar pengetahuan yang didapat dalam kegiatan pengabdian ini dapat diterapkan di kehidupan sehari-hari agar terhindar dari dampak-dampak yang muncul akibat hipertensi yang dibiarkan.

\section{UCAPAN TERIMAKASIH}

Ucapan terimakasih kami sampaikan kepada berbagai pihak, diantaranya kepada pihak kampus kami Program Studi Kesehatan Masyarakat Fakultas Kedokteran Universitas Lambung Mangkurat dan kepada seluruh masyarakat yang telah berkenan mengikuti rangkaian kegiatan penyuluhan dari kami sehingga berjalan dengan baik dan lancar

\section{DAFTAR RUJUKAN}

Adib, M. (2009). Cara Mudah Memahami dan Menghindari Hipertensi Jantung dan Stroke. Yogyakarta: Dianloka Pustaka Populer.

Anggreani, N. \& Nasution, J. D. (2020). Hubungan Pengetahuan dan Sikap Lansia Dengan Riwayat Hipertensi Dalam Pengendalian Tekanan Darah Pada Lansia di Puskesmas Sibolangit Kabupaten Deli Serdang Tahun 2019. Journal of Chemical Information and Modeling.

Febriyanti N, R. \& Nugraha, F. (2020). Penyuluhan Sosial: Membaca Konteks dan Memberdayakan Masyarakat. Bandung: Lekkas.

Isnaini, N. \& Purwito, D. (2019). Edukasi Pengetahuan Hipertensi dan Penatalaksanaan Warga Aisyiah Desa Karang Talun Kidul. Seminar Nasional Pengembangan Sumberdaya Maju Masyarakat Madani Berkrearifan Lokal, 117-120.

Kemenkes RI (2013). Profil Kesehatan Indonesia. Jakarta: Kemenkes RI.

Kemenkes RI (2018). Klasifikasi Hipertensi. Retrieved from: http://p2ptm.kemkes.go.id/infographicp2ptm/hipertensi-penyakit-jantungdan-pembuluhdarah/page/28/klasifikasi-hipertensi

Sidabutar, R. P. \& Wiguno, P. (1999). Ilmu Penyakit Dalam Jilid II. Jakarta: Balai Penerbit FK-UI.

Sunarmi \& Afrida, A. (2019). Pengaruh 
Pendidikan Kesehatan Tentang Diet Hipertensi Terhadap Pengetahuan dan Sikap. Jurnal IImiah Multi Science Kesehatan. 10(1). 92-102.

Tarigan, A. R., Lubis, Z. \& Syarifah (2018). Pengaruh Pengetahuan, Sikap dan Dukungan Keluarga Terhadap Diet Hipertensi di Desa Hulu Kecamatan Pancur Batu Tahun 2016. Jurnal Kesehatan. 11(1). 9-17.

Ulya, Z., Iskandar, A. \& Asih, F. T. (2017). Pengaruh Pendidikan Kesehatan Dengan Media Poster Terhadap Pengetahuan Manajemen Hipertensi Pada Penderita Hipertensi. Jurnal Keperawatan Soedirman. 12(1). 38-46.

WHO (2013). World Health Statistic 2013. Geneva: WHO Press. 